\title{
The implementation of the CLaMS Lagrangian transport core into the chemistry climate model EMAC 2.40.1: application on age of air and transport of long-lived trace species
}

\author{
C. M. Hoppe ${ }^{1, *, * *}$, L. Hoffmann ${ }^{2}$, P. Konopka ${ }^{1}$, J.-U. Grooß ${ }^{1}$, F. Ploeger ${ }^{1}$, G. Günther ${ }^{1}$, P. Jöckel ${ }^{3}$, and R. Müller ${ }^{1}$ \\ ${ }^{1}$ Institute of Energy and Climate Research (IEK-7), Forschungszentrum Jülich GmbH, Jülich, Germany \\ ${ }^{2}$ Jülich Supercomputing Centre (JSC), Forschungszentrum Jülich GmbH, Jülich, Germany \\ ${ }^{3}$ Deutsches Zentrum für Luft- und Raumfahrt (DLR), Institut für Physik der Atmosphäre, Oberpfaffenhofen, Germany \\ *now at: Institute of Energy and Climate Research (IEK-8), Forschungszentrum Jülich GmbH, Jülich, Germany \\ ** now at: Rhenish Institute for Environmental Research, University of Cologne, Cologne, Germany
}

Correspondence to: C. M. Hoppe (c.hoppe@fz-juelich.de)

Received: 25 February 2014 - Published in Geosci. Model Dev. Discuss.: 17 March 2014

Revised: 21 September 2014 - Accepted: 7 October 2014 - Published: 11 November 2014

\begin{abstract}
Lagrangian transport schemes have proven to be useful tools for modelling stratospheric trace gas transport since they are less diffusive than classical Eulerian schemes and therefore especially well suited for maintaining steep tracer gradients. Here, we present the implementation of the full-Lagrangian transport core of the Chemical Lagrangian Model of the Stratosphere (CLaMS) into the ECHAM/MESSy Atmospheric Chemistry model (EMAC). We performed a 10-year time-slice simulation to evaluate the coupled model system EMAC/CLaMS. Simulated zonal mean age of air distributions are compared to age of air derived from airborne measurements, showing a good overall representation of the stratospheric circulation. Results from the new Lagrangian transport scheme are compared to tracer distributions calculated with the standard flux-form semiLagrangian (FFSL) transport scheme in EMAC. The differences in the resulting tracer distributions are most pronounced in the regions of strong transport barriers. The polar vortices are presented as an example for isolated air masses which are surrounded by a strong transport barrier and simulated trace gas distributions are compared to satellite measurements. The analysis of CFC-11, $\mathrm{N}_{2} \mathrm{O}, \mathrm{CH}_{4}$, and age of air in the polar vortex regions shows that the CLaMS Lagrangian transport scheme produces a stronger, more realistic transport barrier at the edge of the polar vortex than the FFSL transport scheme of EMAC. Differences in simulated age of air range up to 1 year in the Arctic polar vor-
\end{abstract}

tex in late winter/early spring. The new coupled model system EMAC/CLaMS thus constitutes a suitable tool for future model studies of stratospheric tracer transport.

\section{Introduction}

Chemistry climate models (CCMs) that allow atmospheric dynamics, transport and chemistry to be described from the surface to the stratosphere and above are key tools for projections of the future development of the stratosphere and in particular of the stratospheric ozone layer (e.g. Eyring et al., 2005; WMO, 2011). Such models are furthermore important for climate modelling because they are able to describe the impact of stratospheric change such as ozone depletion on tropospheric climate and to simulate the stratospheric response to tropospheric perturbations (Shaw and Shepherd, 2008; Thompson and Solomon, 2002; Son et al., 2008). For the description of surface climate change and its decadal variability it is important for the model to have an accurate description of water vapour in the upper troposphere/lower stratosphere (UTLS) region (Solomon et al., 2010; Riese et al., 2012). However, when tested in a processfocused manner against observations, simulations of CCMs still show deficits in several aspects (SPARC, 2010). In particular, a good representation of transport in the vicinity of strong tracer gradients (jet and tropopause) is a challenge for 
the transport schemes of CCMs (e.g. Strahan et al., 2011; SPARC, 2010). Moreover, the fact that the velocity of upward transport throughout the stratosphere is only insufficiently known constitutes an important obstacle for a description of the stratospheric circulation (Brewer-DobsonCirculation) and its change with climate change (Randel and Jensen, 2013; Schoeberl et al., 2012; Ploeger et al., 2012).

In studies using chemistry transport models (CTMs) and CCMs, it has been proven to be successful to use the Lagrangian concept of transport (e.g. McKenna et al., 2002a, b; Konopka et al., 2004; Stenke et al., 2009) in overcoming the inherent numerical diffusivity of Eulerian transport schemes. In a pure Lagrangian transport scheme, transport of chemical tracers is described by an ensemble of air parcels that move along trajectories. These trajectories are calculated based on prescribed wind fields deduced from meteorological analyses or from model simulations. The advantage of this transport representation is that it is inherently non-diffusive and therefore very well suited for simulating transport barriers in the atmosphere.

Here, we describe the integration of the transport core of the Chemical Lagrangian Model of the Stratosphere (CLaMS, McKenna et al., 2002a, b) into the CCM ECHAM/MESSY Atmospheric Chemistry model (EMAC, Jöckel et al., 2005, 2010). CLaMS is especially designed for simulations in the stratosphere and in the UTLS region. There are two main differences of the CLaMS transport scheme in comparison to the standard flux-form semiLagrangian (FFSL) transport scheme in EMAC (Lin and Rood, 1996): first, CLaMS provides a full-Lagrangian transport scheme, which has the advantage of being non-diffusive, as described above. The second difference is the representation of vertical velocities. As most CCMs, EMAC employs a pressure-based grid structure. The vertical velocities for tracer transport in EMAC are calculated by the transport scheme as a residual from the horizontal flux divergence using the continuity equation (Lin, 2004). In contrast, CLaMS vertical coordinates in the stratosphere are defined on levels of constant potential temperature. Vertical velocities are derived from diabatic heating rates. The nearly adiabatic nature of atmospheric large-scale motion, with the flow mainly being along isentropic surfaces, seems to favour use of the isentropic coordinate system (Mahowald et al., 2002). For example, planetary waves propagate approximately on surfaces of constant potential temperature, while the pressure may fluctuate considerably during wave propagation. Crossisentropic motion is determined by diabatic heating rates due to radiation, latent heat, and other diabatic processes like turbulent mixing (Andrews et al., 1987).

Another Lagrangian transport model (ATTILA, Reithmeier and Sausen, 2002) has previously been coupled to the ECHAM climate model. Stenke et al. (2008) show that, compared to the ECHAM model using a semi-Lagrangian transport scheme, the wet bias in stratospheric water vapour could be significantly reduced by using the Lagrangian transport scheme ATTILA. In Stenke et al. (2009), this coupled model was expanded to a chemistry transport model. The simulated $\mathrm{Cl}_{\mathrm{y}}$ distribution could be improved with this coupled model. Although ATTILA and CLaMS are both Lagrangian transport schemes, they differ in many respects, e.g. in the air parcel definition and the mixing algorithm.

The purpose of this study is to introduce the new coupled model system EMAC/CLaMS and to evaluate it. We investigate the impact of the Lagrangian transport on trace gas distributions and compare the results to those calculated with the standard flux-form semi-Lagrangian transport scheme in EMAC. This paper is structured as follows: in the next section, the chemistry transport model CLaMS and the chemistry climate model EMAC are introduced. In particular, the coupling strategy is explained here. In Sect. 3, simulation results of age of air and long-lived trace species from the coupled model system are presented and compared to airborne measurements and satellite climatologies. Section 4 gives the conclusions.

\section{Model description}

\subsection{The Chemical Lagrangian Model of the Stratosphere (CLaMS)}

The CLaMS, a modular CTM, is briefly introduced in this section. The model is described in more detail by McKenna et al. (2002a, b), and Konopka et al. (2004). CLaMS comprises three main modules for Lagrangian advection, mixing and stratospheric chemistry, as well as several other modules for the simulation of various physical and chemical processes in the atmosphere. Due to its full-Lagrangian transport scheme, CLaMS is especially well suited for maintaining atmospheric transport barriers, in particular at the edges of the tropical pipe and the polar vortex (e.g. Steinhorst et al., 2005; Günther et al., 2008; Konopka et al., 2010; Ploeger et al., 2013).

\subsubsection{Trajectory calculation}

The CLaMS trajectory module (TRAJ) performs the fullLagrangian, non-diffusive, three-dimensional advection of an ensemble of air parcels (Sutton et al., 1994). The numerical integration is based on a fourth-order Runge-Kutta scheme.

Required input fields are horizontal and vertical winds, e.g. from ERA-Interim reanalysis products (Dee et al., 2011). The representation of the vertical winds depends on the choice of the vertical coordinate system. It is possible to use different vertical coordinates in CLaMS - e.g. potential temperature $\theta$ in which case vertical winds would be determined as $\dot{\theta}=Q$, with $Q$ the diabatic heating rate. In this study, we use the hybrid $\sigma-\theta$ coordinate $\zeta$, with $\dot{\zeta}$ as vertical velocity, as proposed by Mahowald et al. (2002). The $\zeta$-coordinate combines the terrain-following $\sigma$-coordinate 
( $\sigma=\frac{p}{p_{\mathrm{s}}}$ where $p_{\mathrm{s}}$ is surface pressure) for the troposphere and the $\theta$-coordinate for the radiation-dominated stratosphere, and $\zeta$ is defined as follows:

$\zeta=\theta \cdot f(\sigma)$

with

$f(\sigma)= \begin{cases}\sin \left(\frac{\pi}{2} \frac{1-\sigma}{1-\sigma_{\mathrm{r}}}\right) & \sigma>\sigma_{\mathrm{r}} \\ 1 & \sigma \leq \sigma_{\mathrm{r}}\end{cases}$

The implementation of $\zeta$ as vertical coordinate in CLaMS is described in detail in Konopka et al. (2007, 2012). In the present study, we use $\sigma_{\mathrm{r}}=\frac{p_{\mathrm{r}}}{p_{\mathrm{s}}}$ which means that above the reference height $p_{\mathrm{r}}(300 \mathrm{hPa}$ in this study) $\zeta$ is equal to the potential temperature $\theta$.

\subsubsection{Mixing}

CLaMS comprises a mixing module (MIX), so that the air parcels are not completely isolated, but some exchange takes place in situations where strong flow deformation is present in the atmosphere. This constitutes the irreversible part of the CLaMS transport. The mixing of the air parcels in the CLaMS module MIX is controlled by the horizontal strain and vertical shear of the wind field (McKenna et al., 2002a; Konopka et al., 2007). The mixing routine is usually called every $24 \mathrm{~h}$ after the trajectory transport. One mixing event contains the following steps: first, discrete vertical layers are defined according to an entropy criterion such that each of those layers contains approximately the same number of air parcels (for details see Konopka et al., 2007, 2012). Second, the following procedure is done separately for each layer: nearest neighbours of each air parcel are identified using Delaunay triangulation on a horizontal projection of the vertical layer. If the distance between two neighbouring air parcels exceeds a critical distance $r_{+}^{\mathrm{c}}$ after time step $\Delta t$, as defined in Eq. (3), a new air parcel is inserted in the middle. In cases where two air parcels are closer than a critical distance $r_{-}^{\mathrm{c}}$, they are merged such that they form one new air parcel. In other cases, no mixing occurs. The critical radii $r_{ \pm}^{c}$ are defined as follows (McKenna et al., 2002a):

$r_{ \pm}^{\mathrm{c}}=r_{0} \exp \left( \pm \lambda_{\mathrm{c}} \Delta t\right)$

In Eq. (3), $r_{0}$ is the mean horizontal distance of air parcels in the layer. The critical Lyapunov exponent $\lambda_{c}$, a measure for the deformation in the flow, determines the critical radii $r_{ \pm}^{c}$ and thus the mixing strength in the model. The impact of the uncertainty in the mixing strength is investigated in Konopka et al. (2004) and Riese et al. (2012) through varying the parameter $\lambda_{c}$. The pure Lagrangian trajectory advection by TRAJ (Sect. 2.1.1) is numerically non-diffusive. The mixing adds some diffusion to the CLaMS Lagrangian transport (i.e. advection and mixing). The advantage of the CLaMS mixing procedure is that it is built in a physically based manner, i.e. mixing occurs in regions of strong flow deformation and thus where it is expected in reality.

\subsubsection{Chemistry}

The original CLaMS version contains a detailed stratospheric chemistry scheme (CHEM, McKenna et al., 2002b) involving around 150 species. The numerical solver is based on the ASAD code (Carver et al., 1997). For coupling to a climate model a simplified version of CHEM was used which is more suitable for long-term simulations. The simplified scheme is called every $24 \mathrm{~h}$ and uses daily-mean photolysis rates. It allows the stratospheric loss of long-lived tracers $\left(\mathrm{CCl}_{3} \mathrm{~F}(\mathrm{CFC}-11), \mathrm{CCl}_{2} \mathrm{~F}_{2}(\mathrm{CFC}-12), \mathrm{N}_{2} \mathrm{O}\right.$, and $\left.\mathrm{CH}_{4}\right)$ to be reproduced. It further describes the water vapour production by methane-oxidation in the stratosphere. The simplified chemistry scheme is described in more detail in Pommrich et al. (2014).

\subsection{The chemistry climate model EMAC}

The ECHAM/MESSY Atmospheric Chemistry model (EMAC) is a chemistry climate model (CCM) that comprises the climate model ECHAM5 (Röckner et al., 2006) and the interface structure Modular Earth Submodel System (MESSy, Jöckel et al., 2010). MESSy provides a coupling interface structure to develop Earth system models with the flexibility to vary between many geophysical processes that are included as submodels. MESSy includes various submodels, i.e. for tropospheric and middle atmosphere processes, ocean modules, land surface interaction, and anthropogenic emissions. The first version of MESSy (Jöckel et al., 2006) was developed only for coupling submodels to ECHAM5, whereas the second version (Jöckel et al., 2010) is also suitable for other basemodels, e.g. regional weather forecast models. For the current study, the MESSy version 2.40.1 was used.

MESSy includes a special submodel for dealing with atmospheric tracers. This submodel TRACER is described by Jöckel et al. (2008). It provides the interface structure to couple different external chemistry transport modules to the basemodel. In the standard EMAC setup, tracers are transported using the flux-form semi-Lagrangian transport scheme of Lin and Rood (1996). In the implementation of the scheme by Lin and Rood (1996) here, the horizontal transport is performed using the piece-wise parabolic method (PPM, Carpenter et al., 1990). The vertical transport is based on the use of the Huynh/Van Leer/Lin full monotonicity constraint (see Appendix B in Lin, 2004). The vertical velocities are calculated internally in the transport scheme from the horizontal flux divergence using the continuity equation. 


\subsection{The coupled model system EMAC/CLaMS}

\subsubsection{The MESSy interface structure}

This section provides a short description of the architecture of the MESSy interface. A more detailed description is given in Jöckel et al. (2005, 2010). The code of MESSy is structured, such that each FORTRAN95 module is assigned to one of the following four layers:

- the base model layer (BML): this part contains the source code of the base model. This can be for instance a climate model (ECHAM5 in our study), a simple boxmodel, or a regional weather forecast model.

- The base model interface layer (BMIL): this layer manages data input and output, and the communication between the particular submodels and the base model. Global variables are stored in special structures called "channel objects".

- The submodel interface layer (SMIL): this part of the code connects the particular submodels to the BMIL. It sets pointers to the required global arrays in the BMIL. The SMIL contains the calls of the respective submodel routines for the initialization, time integration, and finalizing phase of the model.

- The submodel core layer (SMCL): the SMCL contains the source code for the calculation of physical and chemical processes as well as diagnostics of the submodels. Examples for submodels in MESSy are parameterizations of gravity waves, emissions of tracers or a mixed-layer ocean.

\subsubsection{Implementation of CLaMS modules}

The CLaMS main modules TRAJ, MIX, and CHEM were modified and integrated as new submodels in the MESSy interface structure. Other submodels, e.g. for the dehydration by cirrus cloud formation (CIRRUS) or for CLaMS boundary conditions (BMIX) were also included. Since the CLaMS modules have been redesigned as independent MESSy submodels, within MESSy they are called CLAMSTRAJ, CLAMSMIX, CLAMSCHEM, etc. For the sake of readability, we name them here throughout the text without the prefix CLAMS.

There are two ways to use these CLaMS submodels in the MESSy interface (Fig. 1). The first option is to run the coupled version with the ECHAM5 basemodel (left box in Fig. 1). In this case, horizontal winds driving the isentropic CLaMS trajectories are calculated by ECHAM5. Likewise, the vertical, cross-isentropic velocities are deduced from diabatic heating rates from the climate model. The heating rates result from several process parameterizations, like radiation, convection and clouds, gravity wave drag, and vertical diffusion. The dominant terms in the heating rate budget are ra-

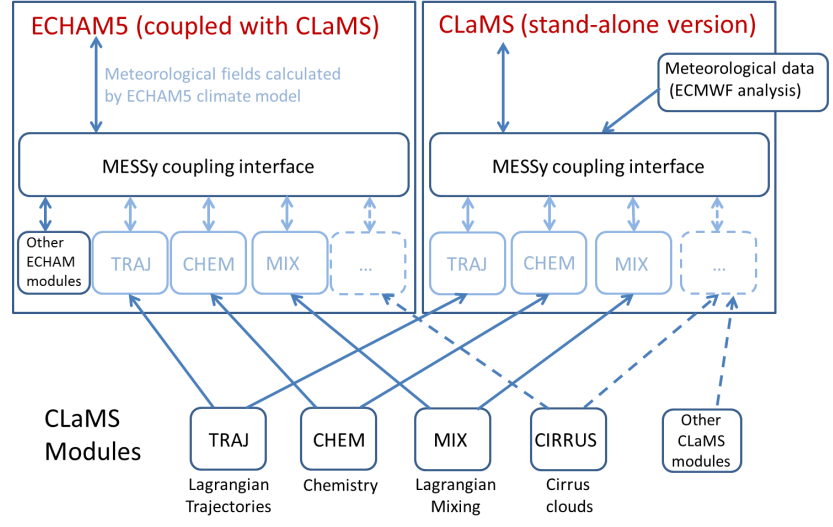

Figure 1. Schematic of the CLaMS modules integrated in the MESSy interface.

diation and (where applicable) latent heat release from cloud formation. The MESSy interface also provides the possibility for two-way coupling between processes. Thus, trace gas distributions derived by CLaMS could serve as input for the EMAC radiation calculation.

The second possible basemodel is the newly developed CLaMS basemodel (right box in Fig. 1). Here, the meteorological input fields are read from external data files, e.g. from ERA-Interim reanalysis data. Running the CLaMS basemodel delivers the same result as the original CLaMS model that is not included in the MESSy interface. The single modules of the original version were represented as individual Fortran90 programs, which were started by a shell script. Technically, the new CLaMS basemodel replaces the shell script that was used to run the original version of CLaMS. In the original version, data exchange between the modules was achieved through NetCDF files. In contrast, in the MESSy version, the communication between the different submodels is carried out via the interface structure in the BMIL, therefore no external data files are required.

\section{Results}

Here we present results of a 10-year time-slice simulation with the EMAC/CLaMS model. In this simulation, two transport schemes were applied with two similar tracer sets. The two transport schemes were run in parallel in the same climate simulation, thus the meteorological fields (e.g. horizontal winds and temperature) were identical. The only exception to this are the vertical wind fields, which were also derived from the same simulation, but using different methods (see Sects. 2.1.1 and 2.2). Here one-way coupling was used, i.e. the trace gas distributions calculated in this study did not influence climate model dynamics. Tracer distributions calculated with the CLaMS full-Lagrangian transport scheme are compared to tracer fields derived from the fluxform semi-Lagrangian transport in EMAC. The transport 
with the full-Lagrangian transport scheme will be referred to as "EMAC/CLaMS" in the following, and the one using the flux-form semi-Lagrangian transport will be denoted "EMAC-FFSL".

A detailed analysis of the zonal mean climatologies of age of air and trace gases from simulation with the coupled model system EMAC/CLaMS will be published in a separate paper which will include a comparison to satellite climatologies and an in-depth discussion on the influence of the different transport schemes and the different vertical velocities on the simulated tracer distributions. In the present work, we focus on the polar vortex regions which constitute an example for a particularly pronounced transport barrier in the stratosphere.

\subsection{Simulation setup}

For this study, we performed a 10-year time-slice simulation with chemical boundary conditions representing the year 2005.

The underlying climate simulation was a free-running ECHAM5 simulation without nudging to observations. The sea surface temperature and sea ice concentration boundary conditions are taken from the Atmospheric Model Intercomparison Project (AMIP II, Hurrell et al., 2008) climatology. The horizontal resolution is T42, which corresponds to a quadratic Gaussian grid with gridboxes of approximately $2.8^{\circ}$ extent in latitude and longitude $(\approx 300 \mathrm{~km}$ at the equator). The grid has 90 vertical levels from the surface up to $0.01 \mathrm{hPa}(\approx 80 \mathrm{~km})$.

Two sets of chemical tracers are set up, one for each of the two transport schemes EMAC/CLaMS and EMAC-FFSL. The tracers include the species for the simplified CLaMS chemistry scheme, as described in Pommrich et al. (2014). Here, we focus on the analysis of the long-lived tracers CFC$11, \mathrm{~N}_{2} \mathrm{O}$, and $\mathrm{CH}_{4}$. The initial and boundary values for the tracer fields are taken from a climatological simulation with the uncoupled CLaMS model (Pommrich et al., 2014) that is driven by ERA-Interim meteorological reanalysis data (Dee et al., 2011).

An age of air tracer is also added to each of the tracer sets (Pommrich et al., 2011), implemented as a passive tracer with a linear increasing lower boundary condition ("clocktracer", Hall and Plumb, 1994). The mean age at a certain position in the atmosphere is derived from the difference between the local tracer value and the current value at the surface.

For the CLaMS transport scheme, about one million air parcels are set up from the surface up to the $2500 \mathrm{~K}$ potential temperature level $(\approx 60 \mathrm{~km})$. The number of air parcels is comparable to the number of gridpoints in the EMAC grid. However, the distribution of the data points is different for the two transport representations, as CLaMS air parcels are initialized in vertical layers that all have the same amount of entropy (Konopka et al., 2007, 2012). Every 24 h, the CLaMS mixing procedure is applied on the ensemble of CLaMS air parcels and the simplified chemistry is calculated. The mixing parameters are set to $\lambda_{\mathrm{c}}=1.2 \mathrm{day}^{-1}$ and $r_{0}=300 \mathrm{~km}$. The boundaries are updated after the mixing procedure.

A similar tracer set is defined in the EMAC gridpoint space for the EMAC-FFSL transport. These tracers are transported by the flux-form semi-Lagrangian transport scheme. The same chemistry algorithm (CLaMS simplified chemistry) as for EMAC/CLaMS is applied on the EMAC-FFSL tracer set. As already mentioned, the same boundary and initial values are used for both tracer sets.

Climatologies have been produced for the EMAC/CLaMS and EMAC-FFSL simulation results. Data are interpolated to the same regular grid structure for the daily output, and monthly mean values are calculated for each month. Then, the respective monthly means for all 10 years of simulation are used for the climatology. Climatologies averaged over the whole simulation period of 10 years have been compared to climatologies derived only from the last five years of output to test if there are large influences of initialization. Only small differences were found (see Fig. 5). Therefore, only the 10 -year climatologies were used for the following analysis.

\subsection{Age of air}

First we present age of air distributions for the verification of the new coupled model system. The age of air diagnostic is suitable for this purpose since mean age is a passive tracer that directly displays transport characteristics. Eluszkiewicz et al. (2000) show that age of air is very sensitive to the choice of the transport scheme.

We show mean age of air for the EMAC/CLaMS and EMAC-FFSL climatologies in comparison to mean age of air derived from measurements in Fig. 2. The latter age of air values are derived from $\mathrm{CO}_{2}$ and $\mathrm{SF}_{6}$ measurements (Andrews et al., 2001; Engel et al., 2009). Figure 2 shows that both models produce a similar age of air distribution, which lies in most cases at or below the lower boundary of the onesigma uncertainty range of the age of air values derived from measurements. Annual zonal mean age at $50 \mathrm{hPa}$ for all latitudes is displayed in the top left panel of Fig. 2. The simulated age of air pattern is consistent with the general features of the stratospheric circulation. There is upwelling of young air masses in the tropics, and downwelling of old air masses in the polar regions. Both simulations exhibit slightly older air in the Southern Hemisphere compared to the Northern Hemisphere. The age in EMAC/CLaMS is slightly younger than EMAC-FFSL in the Southern Hemisphere. The differences in the zonal, annual mean between the two model representations do not exceed 3 months, but regional and seasonal differences may be larger. The tropical profile for EMAC/CLaMS shows younger age than EMAC-FFSL (Fig. 2, top right panel). This indicates that in the case of comparable ascent rates the subtropical transport barriers at the edges of the tropical pipe are stronger in EMAC/CLaMS. 
This means that more mid-latitude air is mixed into the tropical pipe in EMAC-FFSL. In mid-latitudes in the Northern Hemisphere, age of air profiles from the two simulation climatologies are about 1 to 1.5 years younger than the age of air profile derived from $\mathrm{CO}_{2}$ and $\mathrm{SF}_{6}$ measurements (Fig. 2, middle left panel). This is a typical feature in models, thus the profiles shown here are comparable to many models, which are compared in a similar way in SPARC (2010). A comparison of the EMAC/CLaMS and EMACFFSL mid-latitude profiles reveals that the age is younger in EMAC/CLaMS, in the Northern as well as in the Southern Hemisphere (Fig. 2, bottom left panel). However, the difference in age of air is larger in the Southern Hemisphere than in the Northern Hemisphere. The gradient (here: the difference) between the Northern Hemisphere mid-latitude and tropical profile is shown in the middle right panel of Fig. 2. The gradients derived from the simulation climatologies fit well to the measurements at high altitudes down to $30 \mathrm{hPa}$, whereas in the lower stratosphere the gradient in the model climatology is lower than in the observations. The difference between the tropical and mid-latitude profiles is slightly higher in the EMAC/CLaMS simulation for the Northern Hemisphere. In contrast, in the Southern Hemisphere, the gradient for EMAC-FFSL shows higher values (Fig. 2, bottom right panel). The gradient between the tropical and mid-latitude profiles can be used as a diagnostic for the tropical ascent rate (Neu and Plumb, 1999; Strahan et al., 2009; SPARC, 2010), showing that the ascent rate is too fast in both transport representations at low altitudes. However, comparing the vertical velocities in EMAC/CLaMS and EMAC-FFSL, this relatively simple diagnostic does not provide a clear result, since the EMAC/CLaMS gradient is smaller than the EMAC-FFSL gradient in the Southern Hemisphere and larger in the Northern Hemisphere. The differences in the annual, zonal mean ascent rates in EMAC/CLaMS and EMAC-FFSL are comparably small. However, the wind fields show a seasonal variation in strength and location which leads to hemispheric differences in the trace gas distributions. The analysis of these complex interactions between seasonal variations in the vertical velocity and trace gas distributions are ongoing work and will be discussed in a future publication.

Zonal mean trace gas climatologies from EMAC/CLaMS were also used to derive the relative lifetime of CFC-11 and CFC-12 (Hoffmann et al., 2014). The results compare very well with lifetimes derived independently from various satellite climatologies. The lifetime ratio of CFC-11 and CFC-12 from the EMAC/CLaMS simulation yields $0.48(0.40-0.55)$. From the satellite climatologies Hoffmann et al. (2014) deduce lifetime ratios ranging from $0.46(0.38-0.54)$ to 0.47 $(0.39-0.54)$. The good agreement between the model deduced and observationally deduced lifetimes provides further confidence in the representation of transport and chemistry of long-lived tracers in the EMAC/CLaMS model system. The results also correspond very well with the recommendations
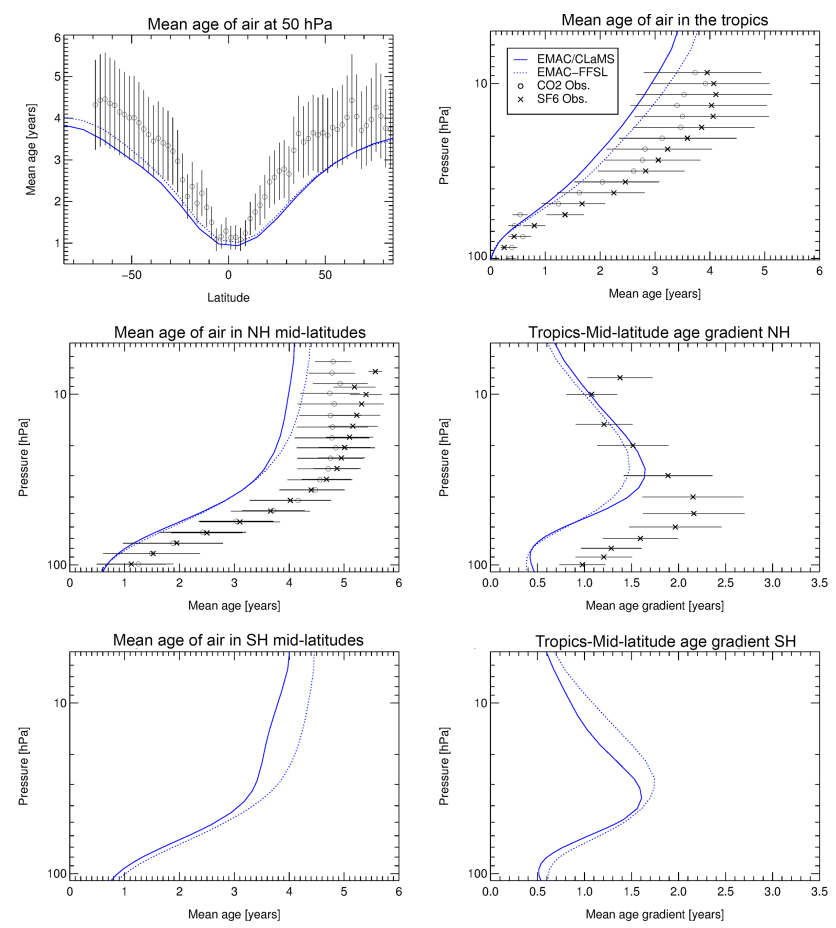

Figure 2. Zonal mean age of air [years]: simulation results of EMAC/CLaMS as solid blue line, EMAC-FFSL as dotted blue line, and mean age from measurements $\left(\mathrm{SF}_{6}\right.$, black crosses; $\mathrm{CO}_{2}$, black circles; Andrews et al., 2001; Engel et al., 2009), shown with $1 \sigma$ uncertainties. The top left panel shows zonal mean age of air at $50 \mathrm{hPa}$. The top right panel shows tropical profiles $\left(10^{\circ} \mathrm{N}-10^{\circ} \mathrm{S}\right)$, the middle left panel $\mathrm{NH}$ mid-latitude profiles $\left(35-45^{\circ} \mathrm{N}\right)$ and the bottom left panel SH mid-latitude profiles $\left(35-45^{\circ} \mathrm{S}\right)$. The difference between the mid-latitude and the tropical profiles are presented in the middle right panel for the Northern Hemisphere, and the bottom right panel for the Southern Hemisphere.

for the lifetimes of CFCs by SPARC (2013) which provide a lifetime ratio of CFC-11 and CFC-12 of 0.51 (0.35-0.76).

\subsection{Representation of polar vortices}

In this section we compare the representation of the Arctic and Antarctic polar vortices in the two transport schemes. The edge of the polar vortex forms a strong transport barrier in the stratosphere (e.g. Steinhorst et al., 2005; Günther et al., 2008). Inside the vortex, diabatic descent of air masses from high altitudes leads to low concentrations of trace gases which are of tropospheric origin and have a stratospheric sink (e.g. Müller et al., 1996). These isolated conditions are crucial for polar ozone depletion. However, the simulation of a highly isolated vortex is a difficult task for climate models with limited spatial resolution. SPARC (2010) show that many CCMs do not form a sufficiently isolated Antarctic polar vortex. The problem of the isolation of the polar vortex is often even more pronounced for Arctic conditions (SPARC, 2010). 

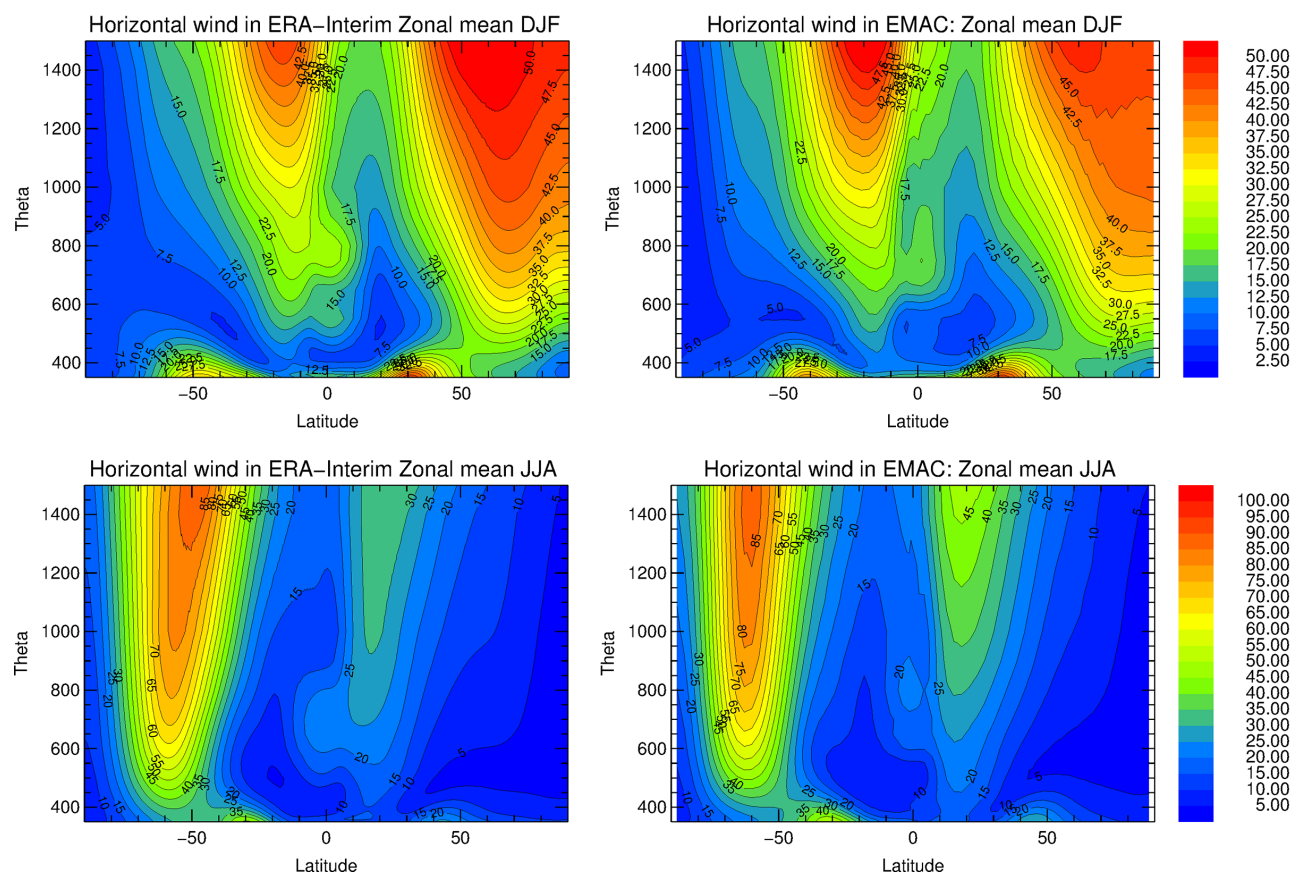

Figure 3. Zonal mean of horizontal wind speed $\left[\mathrm{m} \mathrm{s}^{-1}\right.$ ] from ERA-Interim climatology (left column) and EMAC climatology (right column): December to February (DJF, top panels), and July to August (JJA, bottom panels).

When comparing the model performance in the case of vortex isolation against observations, it is important to assess the quality of the simulated horizontal wind. Therefore, before validating the transport schemes, we first compare the mean horizontal wind in EMAC with the mean horizontal wind in ERA-Interim in Fig. 3. We find that ERAInterim horizontal winds are stronger in the Northern Hemispheric polar jet stream. In the Southern Hemisphere, horizontal winds are also slightly stronger in ERA-Interim than in EMAC below $800 \mathrm{~K}$. Thus the polar vortex is weaker in EMAC than in ERA-Interim and trace gas gradients are also expected to be moderately weaker in the simulation results than in satellite climatologies, independently of the employed the transport scheme.

\subsubsection{Antarctic polar vortex}

Figure 4 shows horizontal age of air distributions of EMACFFSL and EMAC/CLaMS at $450 \mathrm{~K}$ for August and October in the Southern Hemisphere. In August (top panels), there are older air masses inside the vortex in EMAC/CLaMS than in EMAC-FFSL. Inside the vortex the air is up to 0.5 years younger in EMAC-FFSL. In contrast, EMAC/CLaMS shows younger air outside the vortex. In October (bottom panels), the age of air differences inside the vortex have increased to values of 0.8 years. The differences are larger than in October because the processes that dominate the vortex evolution are different. During August, diabatic downwelling is the most important process in the vortex. It is found that in August the diabatic vertical velocities in EMAC/CLaMS are larger in the downwelling region of the polar vortex than the respective kinematic vertical velocities in EMAC-FFSL. This leads to the small differences in age of air in August that are displayed in the top right panel of Fig. 4. However, in October downwelling weakens so that the relative impact of horizontal transport through the vortex edge and mixing on the age of air distribution increases (Gerber, 2012). During the period when the transport barrier controls horizontal mixing, the differences in age of air are larger than during the earlier period when downwelling is the most important process.

Similar to age of air, the simulated patterns of long-lived tracers are mainly controlled by transport but allow a comparison against measurements. For the Antarctic polar vortex region, we also compared vertical profiles of simulated CFC-11 and $\mathrm{CH}_{4}$ with profiles from measurement climatologies of the Atmospheric Chemistry Experiment-Fourier Transform Spectrometer (ACE-FTS). The ACE-FTS climatology (Jones et al., 2012) contains monthly zonal mean values for 14 species. It does not include error budget estimates, but comparisons with measurements from other instruments show differences in the order of $10 \%$ for CFC-11 and $\mathrm{CH}_{4}$ (Jones et al., 2012). The climatology includes ACEFTS measurements from February 2004 to February 2009.

The top panels in Fig. 5 show profiles for September in the 80 to $70^{\circ} \mathrm{S}$ latitude bin. At this time, the vortex is still stable and clearly separated from mid-latitude air. The profile of CFC-11 from EMAC/CLaMS is in good agreement with the ACE-FTS climatology, although slightly higher at $17-19 \mathrm{~km}$ altitude. However, the EMAC-FFSL simulation 

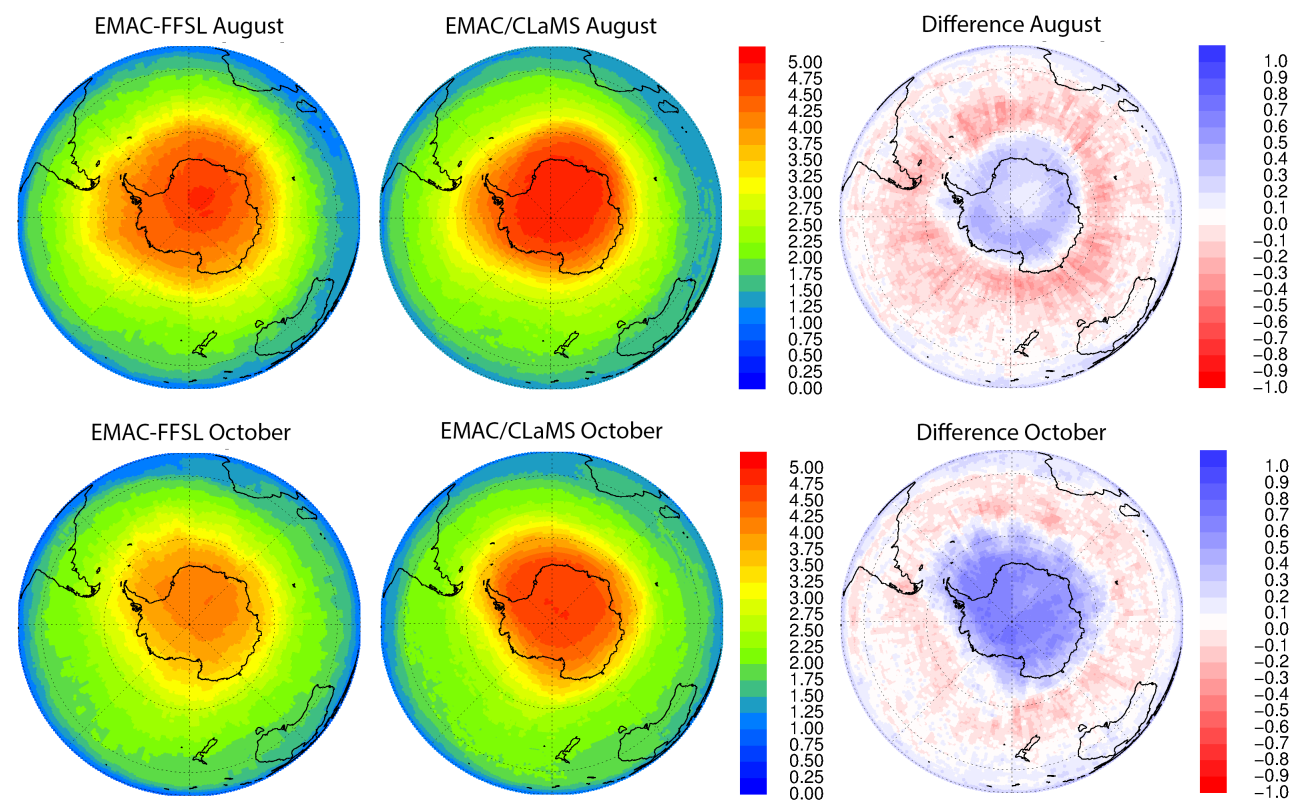

Figure 4. Age of air [years] at $450 \mathrm{~K}$ for August (top panels) and October (bottom panels) in the Southern Hemisphere. Left and middle panels display age of air distributions for EMAC-FFSL and EMAC/CLaMS, respectively. Right panels show the absolute difference in mean age of air [years] (EMAC/CLaMS - EMAC-FFSL). Blue colour denotes older air in EMAC/CLaMS, and red colour denotes older air in EMAC-FFSL.
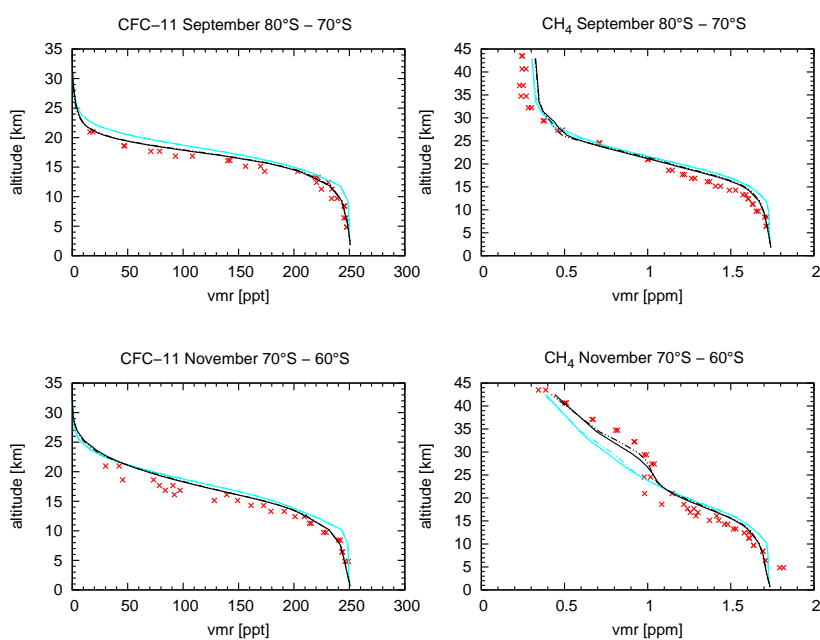

Figure 5. Profiles of $\mathrm{CFC}-11$ and $\mathrm{CH}_{4}$ for different months and latitude bins: ACE-FTS climatology is shown in red, blue profiles display simulation results with EMAC-FFSL transport and black profiles show results with EMAC/CLaMS full Lagrangian transport. Solid lines show mean values over 10 years of simulation, whereas dash-dotted lines indicate results for only the last 5 years of simulation. The profiles for the simulations have been generated as follows: daily output have been interpolated onto a regular grid, then monthly mean values are calculated. The mean value of all simulated years for the respective latitude bins is shown here. ACE-FTS climatological profiles are shown for 72.5 and $77.5^{\circ} \mathrm{S}$ in the top panels, and for 62.5 and $67.5^{\circ} \mathrm{S}$ in the bottom panels, respectively. produces higher CFC-11 mixing ratios for all altitudes. This shows that the transport barrier at the edge of the polar vortex is weaker in the EMAC-FFSL simulation which results in an overestimated mixing across the vortex edge.

The top right panel of Fig. 5 displays the respective profiles of $\mathrm{CH}_{4}$. Here, the same pattern as in the CFC-11 profiles is visible. The EMAC-FFSL profiles show higher concentrations than the satellite climatology. EMAC/CLaMS also exhibits higher $\mathrm{CH}_{4}$, but is closer to the ACE-FTS measurements up to $20 \mathrm{~km}$. At higher altitudes above $30 \mathrm{~km}$ both models show higher $\mathrm{CH}_{4}$ mixing ratios than observed. Overall, EMAC/CLaMS transport leads to an improvement of the $\mathrm{CH}_{4}$ simulation in the vortex region, although it results in still higher mixing ratios than in the satellite climatology.

The bottom panels in Fig. 5 present similar plots for November for the latitude bin from 70 to $60^{\circ} \mathrm{S}$. In this month, the Antarctic vortex begins to break up. This process starts at high altitudes. The weakening of the vortex boundary is clearly visible in the $\mathrm{CH}_{4}$ profiles in the bottom right panel. The ACE-FTS profile exhibits a pronounced kink at 20 to $25 \mathrm{~km}$ altitude. This kink appears in the profile because the vortex air masses above $25 \mathrm{~km}$ are mixed with $\mathrm{CH}_{4}$-rich air from mid-latitudes. The kink is also visible in the EMAC/CLaMS profiles, although it is not as distinct as in the ACE-FTS climatology. The EMAC/CLaMS profiles in the latitude range from 90 to $70^{\circ} \mathrm{S}$ also feature this kink, but at these most southern latitudes there are no ACE-FTS measurements available for comparison. In the EMAC-FFSL profiles, this kink is not visible. These results indicate that 

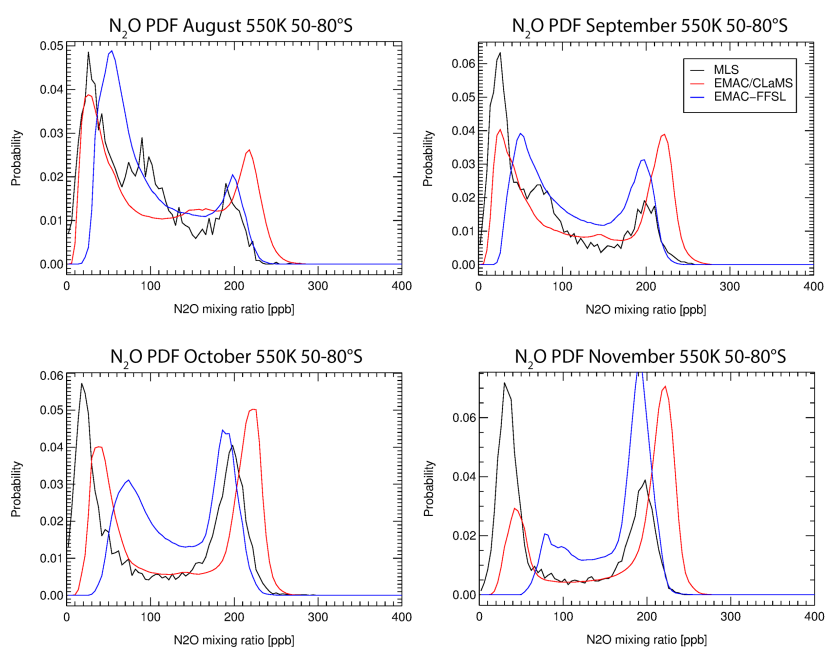

Figure 6. PDF at $550 \mathrm{~K}$ for $\mathrm{N}_{2} \mathrm{O}$ mixing ratio from $50-80^{\circ} \mathrm{S}$ for the months August to November. Blue lines show EMAC-FFSL simulations, red lines EMAC/CLaMS simulations, and black lines represent MLS measurements.

the vortex breakup is much better represented in the CLaMS Lagrangian transport. The kink is not visible in the respective CFC-11 profiles (bottom left panel), because the concentrations are too low to show indications of mixing between polar and mid-latitude air in the altitude range where the beginning of the vortex breakup occurs. The CFC-11 profiles of November are another example for the overall pattern of differences between the two transport schemes: with the CLaMS full-Lagrangian transport, it is possible to produce trace gas distributions that indicate a stronger polar vortex than in EMAC-FFSL, but still weaker than in the satellite climatology, which seems to be linked to the weaker horizontal winds in EMAC (see Fig. 3).

In Fig. 6 we show $\mathrm{N}_{2} \mathrm{O}$ probability density functions (PDFs) at $550 \mathrm{~K}$ from $50-80^{\circ} \mathrm{S}$ for the months August to November. Here, EMAC/CLaMS and EMAC-FFSL results are compared to satellite data from measurements of the Microwave Limb Sounder (MLS) onboard the NASA Aura satellite from 2005 to 2012. The satellite data used here are MLS version 3.3 data (Livesey et al., 2011). The PDFs show a two-peak structure, indicating the separated air masses inside and outside the polar vortex. The peak at lower $\mathrm{N}_{2} \mathrm{O}$ mixing ratios at about $30 \mathrm{ppb}$ characterizes the air inside the vortex. In EMAC-FFSL the lowest observed values are not reached, which indicates either that the downwelling in this model representation is too weak or that the in-mixing from mid-latitudes too strong, or both. It is also visible that the vortex breaks up too early in EMAC-FFSL, since in October the vortex peak has nearly vanished completely. In EMAC/CLaMS, the peak position is captured well in most months except for October. The peak in EMAC/CLaMS is less pronounced than in the MLS data, but the vortex boundary is less penetrable than in EMAC-FFSL. The second peak around $200 \mathrm{ppb}$ indicates mid-latitude air. The mid-latitude peak is well captured in EMAC-FFSL. In EMAC/CLaMS, the peak value is about $20 \mathrm{ppb}$ higher than in the measurements. The separation (i.e. the range of low probability values) between the two peaks of the PDF is an indicator for the strength of the transport barrier at the edge of the polar vortex. Here, using EMAC/CLaMS leads to a clear improvement compared to EMAC-FFSL. The separation between the two peaks is well captured in the Lagrangian transport representation. The comparison of $\mathrm{CH}_{4}$ PDFs of EMAC/CLaMS and EMAC-FFSL with HALOE measurements (Grooß and Russell, 2005) shows similar results (not shown).

The polar vortex edge is characterized by strong horizontal gradients of trace gases. For this study, $\mathrm{N}_{2} \mathrm{O}$ gradients from the simulation climatologies are compared to gradients in monthly climatologies from MLS measurements from 2005 to 2012. The MLS data have been interpolated on vertical pressure levels for each profile, binned horizontally (lat $\times$ long) and averaged for each month. MLS scans about 3500 profiles a day, thereby providing a high-frequency sampling of the global atmosphere and good statistics for creating global monthly zonal mean climatologies. For the comparison, the simulation results have been vertically smoothed in a similar way as the averaging kernel of the MLS retrievals smoothes the atmospheric profiles. Ploeger et al. (2013) show that this procedure is necessary to obtain comparable results, especially in the lower stratospheric polar regions. Figure 7 shows the absolute value of the horizontal $\mathrm{N}_{2} \mathrm{O}$ gradients on the isentropic surface at $450 \mathrm{~K}$ for September. The left panel displays the EMAC-FFSL results, the panel in the middle the gradient in EMAC/CLaMS, and the right panel the MLS climatological values. It is clearly visible that the $\mathrm{N}_{2} \mathrm{O}$ gradient is too weak in the EMAC-FFSL transport, with maximum values around $4.5 \times 10^{-5} \mathrm{ppbm}^{-1}$. The MLS data exhibit maximum values of $7.0 \times 10^{-5} \mathrm{ppbm}^{-1}$. The EMAC/CLaMS $\mathrm{N}_{2} \mathrm{O}$ gradient, calculated with the full Lagrangian transport scheme, shows maximum values of $6.0 \times 10^{-5} \mathrm{ppb} \mathrm{m}^{-1}$. These values are still smaller than those found in the satellite data set, but they show a clear improvement in comparison to the flux-form semi-Lagrangian transport scheme.

\subsubsection{Arctic polar vortex}

This section presents age of air distributions in the Arctic polar vortex region at the end of winter. As the Arctic polar vortex shows substantial interannual variability, more than the Antarctic polar vortex, we do not analyse results from the 10-year climatology here. Instead, monthly mean values from the second year of the time-slice simulation are shown as an example.

Figure 9 shows age of air distributions in the Northern Hemisphere at the $450 \mathrm{~K}$ potential temperature level. In February, the EMAC/CLaMS simulation shows a more pronounced pattern in the age of air distribution, which is the result of a stronger polar vortex barrier and downwelling. 

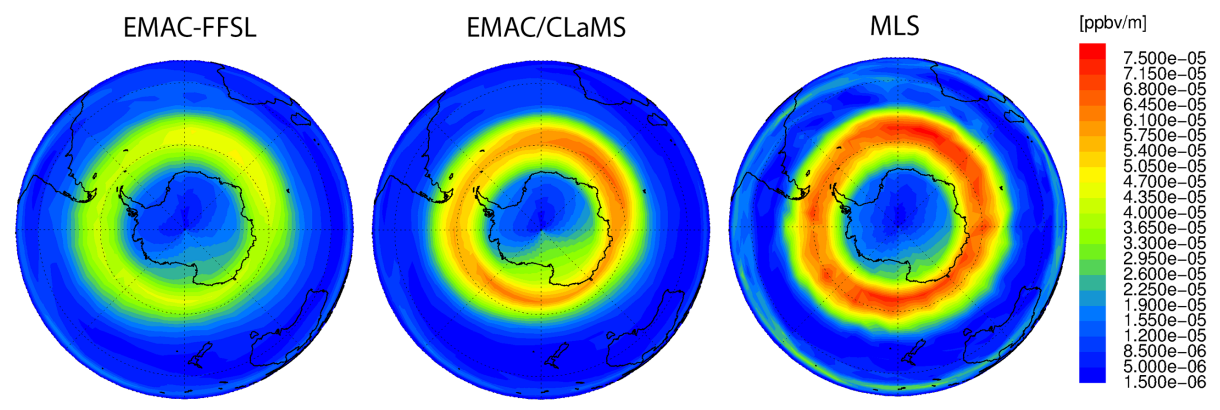

Figure 7. Horizontal gradient of $\mathrm{N}_{2} \mathrm{O}$ in September on the $450 \mathrm{~K}$ isentropic surface.
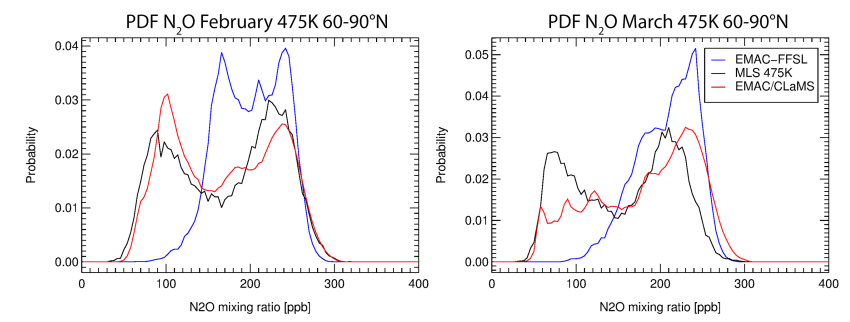

Figure 8. $\mathrm{PDF}$ at $475 \mathrm{~K}$ for $\mathrm{N}_{2} \mathrm{O}$ mixing ratio from $60-90^{\circ} \mathrm{N}$ for the months February and March. Blue lines show EMAC-FFSL simulations, red lines EMAC/CLaMS simulations, and black lines represent MLS measurements.

The air inside the vortex is older and the gradient at the vortex edge is stronger when using the full-Lagrangian transport scheme. The absolute differences for age of air in February are displayed in the top right panel. This plot shows that the maximum difference in mean age of air is located inside the vortex and reaches values up to one year.

In March the vortex has split into two parts (see bottom panels in Fig. 9). This structure is visible in both transport schemes, but it is more pronounced in EMAC/CLaMS. In the EMAC-FFSL representation, stronger mixing of air masses from inside and outside the vortex has taken place. Again, the differences in age of air are largest (up to 1 year) in the regions of the polar vortex.

In Fig. 8 we compare $\mathrm{N}_{2} \mathrm{O}$ PDFs from $60-90^{\circ} \mathrm{N}$ for February and March with MLS measurements, similar to the analysis for the Southern Hemisphere. The peaks of the Northern Hemisphere PDFs are wider than in the PDFs for the Antarctic, which illustrates the larger variability of the Arctic polar vortex. The PDFs show the problems of EMACFFSL in representing the Arctic polar vortex. In February, the peak $\mathrm{N}_{2} \mathrm{O}$ mixing ratio in EMAC-FFSL of $170 \mathrm{ppb}$ is much higher than in the measurements, for which the peak value is located around $100 \mathrm{ppb}$. The separation between the polar vortex air and the mid-latitude air is very weak in EMAC-FFSL. In March, the two-peak structure vanishes in the EMAC-FFSL PDF. EMAC/CLaMS shows improved vortex isolation compared to EMAC-FFSL. In February, the structure of the $\mathrm{N}_{2} \mathrm{O}$ PDF from measurements is well repre- sented by EMAC/CLaMS. In March, low $\mathrm{N}_{2} \mathrm{O}$ mixing ratios below $100 \mathrm{ppb}$ inside the vortex appear in EMAC/CLaMS, but they occur less often than in the measurements. Nonetheless, this constitutes a clear improvement compared to the EMAC-FFSL simulation, where no vortex structure is visible in the $\mathrm{N}_{2} \mathrm{O}$ PDF in March.

The differences in age of air between EMAC-FFSL and EMAC/CLaMS are larger in the Northern Hemispheric vortex than in the Southern Hemispheric vortex. This can be explained by the fact that planetary wave activity is stronger in the Arctic than in the Antarctic. Thus, isentropic Rossby waves disturb the zonal symmetry of the Arctic polar vortex much more strongly than of the almost circumpolar vortex in the Antarctic stratosphere. In such a case, a Lagrangian transport scheme has an advantage over the FFSL approach by minimizing the numerical mixing in the vicinity of a disturbed transport barrier like the vortex edge. The differences between EMAC-FFSL and EMAC/CLaMS due to mixing seem to be larger than the differences due to vertical velocities. This is consistent with the analysis for the Southern Hemisphere, where the differences in age of air are most pronounced in October, when the impact of downwelling decreases and the impact of in-mixing into the vortex increases.

\section{Conclusions}

The full-Lagrangian CTM CLaMS has successfully been coupled to the chemistry climate model EMAC. First results show that the new model system with coupled transport is able to simulate reasonable distributions of age of air and long-lived trace species such as CFC-11, $\mathrm{CH}_{4}$, and $\mathrm{N}_{2} \mathrm{O}$. Differences to the flux-form semi-Lagrangian transport scheme are most pronounced in the regions of strong transport barriers. This is demonstrated for Arctic and Antarctic polar vortices. The results show that when employing the Lagrangian transport scheme a stronger, more realistic transport barrier at the vortex edge is simulated. The newly developed coupled model presented here therefore constitutes a suitable tool for future model studies, especially for regions in the upper troposphere and lower stratosphere where transport barriers are of crucial importance. 

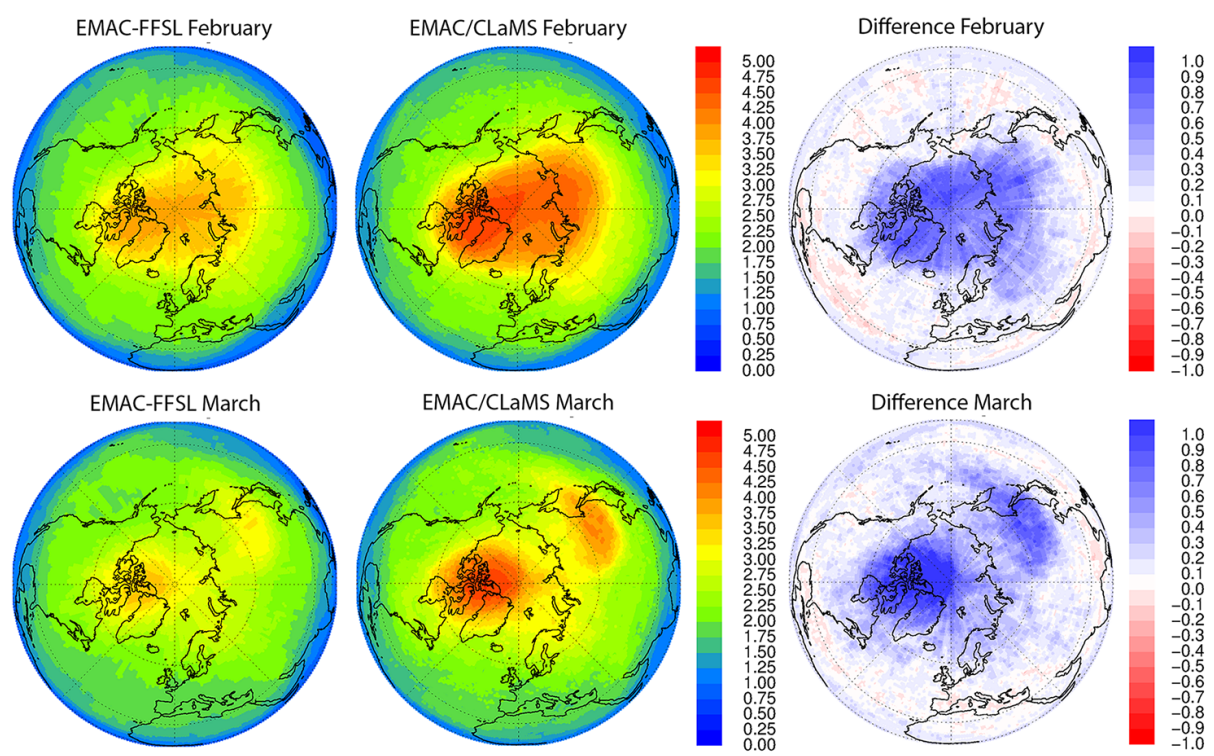

Figure 9. Age of air [years] at $450 \mathrm{~K}$ for February (top panels) and March (bottom panels) in the Northern Hemisphere. Left and middle panels display age of air distributions for EMAC-FFSL and EMAC/CLaMS, respectively. Right panels show the absolute difference in mean age of air [years] (EMAC/CLaMS - EMAC-FFSL). Blue colour denotes older air in EMAC/CLaMS, and red colour denotes older air in EMAC-FFSL.

\section{Code availability}

The Modular Earth Submodel System (MESSy) is continuously further developed and applied by a consortium of institutions. The usage of MESSy and access to the source code is licensed to all affiliates of institutions which are members of the MESSy Consortium. Institutions can be a member of the MESSy Consortium by signing the MESSy Memorandum of Understanding. More information can be found on the MESSy Consortium Website (http://www.messy-interface. org). The new CLaMS submodels are not part of the current MESSy version 2.50, but they will be included in future versions.

Acknowledgements. We thank N. Thomas for programming support. We also thank ECMWF for providing the reanalysis data. The ACE-FTS climatology was provided by the University of Waterloo, Canada. The MLS data were obtained from the NASA Goddard Earth Sciences Data and Information Center. We also acknowledge the Jülich Supercomputing Center (JSC) at Forschungszentrum Jülich for providing computing time and support (project number JIEK71).

The service charges for this open access publication have been covered by a Research Centre of the Helmholtz Association.

Edited by: A. Stenke

\section{References}

Andrews, A. E., Boering, K. A., Daube, B. C., Wofsy, S. C., Loewenstein, M., Jost, H., Podolske, J. R., Webster, C. R., Herman, R. L., Scott, D. C., Flesch, G. J., Moyer, E. J., Elkins, J. W., Dutton, G. S., Hurst, D. F., Moore, F. L., Ray, E. A., Romashkin, P. A., and Strahan, S. E.: Mean ages of stratospheric air derived from in situ observations of $\mathrm{CO}_{2}, \mathrm{CH}_{4}$, and $\mathrm{N}_{2} \mathrm{O}$, J. Geophys. Res.,106, 32295-32314, doi:10.1029/2001JD000465, 2001.

Andrews, D. G., Holton, J. R., and Leovy, C. B.: Middle Atmosphere Dynamics, Academic Press, San Diego, 489 pp., 1987.

Carpenter, R. L., Droegemeier, K. K., Woodward, P. R., and Hane, C. E.: Application of the Piecewise Parabolic Method (PPM) to meteorological modeling, Mon. Weather Rev., 118, 586-612, 1990.

Carver, G. D., Brown, P. D., and Wild, O.: The ASAD atmospheric chemistry integration package and chemical reaction database, Comput. Phys. Commun., 105, 197-215, 1997.

Dee, D. P., Uppala, S. M., Simmons, A. J., Berrisford, P., Poli, P., Kobayashi, S., Andrae, U., Balmaseda, M. A., Balsamo, G., Bauer, P., Bechtold, P., Beljaars, A. C. M., van de Berg, L., Bidlot, J., Bormann, N., Delsol, C., Dragani, R., Fuentes, M., Geer, A. J., Haimberger, L., Healy, S. B., Hersbach, H., Hólm, E. V., Isaksen, L., Kållberg, P., Köhler, M., Matricardi, M., McNally, A. P., Monge-Sanz, B. M., Morcrette, J. J., Park, B. K., Peubey, C., de Rosnay, P., Tavolato, C., Thépaut, J. N., and Vitart, F.: The ERA-Interim reanalysis: configuration and performance of the data assimilation system, Q. J. Roy. Meteor. Soc., 137, 553-597, 2011.

Eluszkiewicz, J., Hemler, R., Mahlman, J., Bruhwiler, L., and Takacs, L.: Sensitivity of age-of-air calculations to the choice of advection scheme, J. Atmos. Sci., 57, 3185-3201, 2000. 
Engel, A., Möbius, T., Bönisch, H., Schmidt, U., Heinz, R., Levin, I., Atlas, E., Aoki, S., Nakazawa, T., Sugawara, S., Moore, F., Hurst, D., Elkins, J., Schauffler, S., Andrews, A., and Boering, K.: Age of stratospheric air unchanged within uncertainties over the past 30 years, Nat. Geosci., 2, 28-31, doi:10.1038/ngeo388, 2009.

Eyring, V., Harris, N. R. P., Rex, M., Shepherd, T. G., Fahey, D. W., Amanatidis, G. T., Austin, J., Chipperfield, M. P., Dameris, M., Forster, P., Graf, H. F., Nagashima, T., Newman, P. A., Pawson, S., Prather, M. J., Pyle, J. A., Salawitch, R. J., Santer, B. D., and Waugh, D. W.: A strategy for process-oriented validation of coupled chemistry-climate models, B. Am. Meteorol. Soc., 86, 1117-1133, 2005.

Gerber, E. P.: Stratospheric versus tropospheric control of the strength and structure of the Brewer-Dobson Circulation, J. Atmos. Sci., 69, 2857-2877, 2012.

Grooß, J.-U. and Russell III, James M.: Technical note: A stratospheric climatology for $\mathrm{O}_{3}, \mathrm{H}_{2} \mathrm{O}, \mathrm{CH}_{4}, \mathrm{NO}_{\mathrm{x}}, \mathrm{HCl}$ and $\mathrm{HF}$ derived from HALOE measurements, Atmos. Chem. Phys., 5, 2797-2807, doi:10.5194/acp-5-2797-2005, 2005.

Günther, G., Müller, R., von Hobe, M., Stroh, F., Konopka, P., and Volk, C. M.: Quantification of transport across the boundary of the lower stratospheric vortex during Arctic winter 2002/2003, Atmos. Chem. Phys., 8, 3655-3670, doi:10.5194/acp-8-36552008, 2008.

Hall, T. M. and Plumb, R. A.: Age as a diagnostic of stratospheric transport, J. Geophys. Res., 99, 1059-1070, 1994.

Hoffmann, L., Hoppe, C. M., Müller, R., Dutton, G. S., Gille, J. C., Griessbach, S., Jones, A., Meyer, C. I., Spang, R., Volk, C. M., and Walker, K. A.: Stratospheric lifetime ratio of CFC-11 and CFC-12 from satellite and model climatologies, Atmos. Chem. Phys. Discuss., 14, 16865-16906, doi:10.5194/acpd-14-168652014, 2014.

Hurrell, J. W., Hack, J. J., Shea, D., Caron, J. M., and Rosinski, J.: A new sea surface temperature and sea ice boundary dataset for the Community Atmosphere Model, J. Climate, 21, 5145-5153, 2008.

Jöckel, P., Sander, R., Kerkweg, A., Tost, H., and Lelieveld, J.: Technical Note: The Modular Earth Submodel System (MESSy) - a new approach towards Earth System Modeling, Atmos. Chem. Phys., 5, 433-444, doi:10.5194/acp-5-433-2005, 2005.

Jöckel, P., Tost, H., Pozzer, A., Brühl, C., Buchholz, J., Ganzeveld, L., Hoor, P., Kerkweg, A., Lawrence, M. G., Sander, R., Steil, B., Stiller, G., Tanarhte, M., Taraborrelli, D., van Aardenne, J., and Lelieveld, J.: The atmospheric chemistry general circulation model ECHAM5/MESSy1: consistent simulation of ozone from the surface to the mesosphere, Atmos. Chem. Phys., 6, 5067-5104, doi:10.5194/acp-6-5067-2006, 2006.

Jöckel, P., Kerkweg, A., Buchholz-Dietsch, J., Tost, H., Sander, R., and Pozzer, A.: Technical Note: Coupling of chemical processes with the Modular Earth Submodel System (MESSy) submodel TRACER, Atmos. Chem. Phys., 8, 1677-1687, doi:10.5194/acp8-1677-2008, 2008.

Jöckel, P., Kerkweg, A., Pozzer, A., Sander, R., Tost, H., Riede, H., Baumgaertner, A., Gromov, S., and Kern, B.: Development cycle 2 of the Modular Earth Submodel System (MESSy2), Geosci. Model Dev., 3, 717-752, doi:10.5194/gmd-3-717-2010, 2010.

Jones, A., Walker, K. A., Jin, J. J., Taylor, J. R., Boone, C. D., Bernath, P. F., Brohede, S., Manney, G. L., McLeod, S., Hughes,
R., and Daffer, W. H.: Technical Note: A trace gas climatology derived from the Atmospheric Chemistry Experiment Fourier Transform Spectrometer (ACE-FTS) data set, Atmos. Chem. Phys., 12, 5207-5220, doi:10.5194/acp-12-5207-2012, 2012.

Konopka, P., Steinhorst, H., Grooss, J., Günther, G., Müller, R., Elkins, J., Jost, H., Richard, E., Schmidt, U., Toon, G., and McKenna, D.: Mixing and ozone loss in the 1999-2000 Arctic vortex: simulations with the three-dimensional Chemical Lagrangian Model of the Stratosphere (CLaMS), J. Geophys. Res., 27, D02315, doi:10.1029/2003JD003792, 2004.

Konopka, P., Günther, G., Müller, R., dos Santos, F. H. S., Schiller, C., Ravegnani, F., Ulanovsky, A., Schlager, H., Volk, C. M., Viciani, S., Pan, L. L., McKenna, D.-S., and Riese, M.: Contribution of mixing to upward transport across the tropical tropopause layer (TTL), Atmos. Chem. Phys., 7, 3285-3308, doi:10.5194/acp-7-3285-2007, 2007.

Konopka, P., Grooß, J.-U., Günther, G., Ploeger, F., Pommrich, R., Müller, R., and Livesey, N.: Annual cycle of ozone at and above the tropical tropopause: observations versus simulations with the Chemical Lagrangian Model of the Stratosphere (CLaMS), Atmos. Chem. Phys., 10, 121-132, doi:10.5194/acp-10-121-2010, 2010.

Konopka, P., Ploeger, F., and Müller, R.: Entropy-Based and Static Stability-Based Lagrangian Model Grids, in: Geophysical Monograph Series: Lagrangian Modeling of the Atmosphere, vol. 200, edited by: Lin, J., American Geophysical Union, Washington, DC, doi:10.1029/2012GM001253, 99-109, 2012.

Lin, S. and Rood, R.: Multidimensional flux-form semi-Lagrangian transport schemes, Mon. Weather Rev., 124, 2046-2070, 1996.

Lin, S.-J.: A "vertically Lagrangian" finite-volume dynamical core for global models, Weather Rev., 132, 2293-2307, 2004.

Livesey, N., Read, W., Froidevaux, L., Lambert, A., Manney, G., Pumphrey, H., Santee, M., Schwartz, M., Wang, S., Cofeld, R., Cuddy, D., Fuller, R., Jarnot, R., Jiang, J., Knosp, B., Stek, P., Wagner, P., and Wu, D.: Earth Observing System (EOS) Aura Microwave Limb Sounder MLS version 3.3 level 2 data quality and description document, Tech. rep., Jet Propulsion Laboratory, 2011.

Mahowald, N., Plumb, R., Rasch, P., del Corral, J., Sassi, F., and Heres, W.: Stratospheric transport in a three-dimensional isentropic coordinate model, J. Geophys. Res., 107, ACH 3-1-ACH 3-14, doi:10.1029/2001JD001313, 2002.

McKenna, D. S., Konopka, P., Grooß, J.-U., Günther, G., Müller, R., Spang, R., Offermann, D., and Orsolini, Y.: A new Chemical Lagrangian Model of the Stratosphere (CLaMS) 1. Formulation of advection and mixing, J. Geophys. Res., 107, ACH 15-1-ACH 15-15, doi:10.1029/2000JD000114, 2002a.

McKenna, D. S., Grooß, J.-U., Günther, G., Konopka, P., Müller, R., Carver, G., and Sasano, Y.: A new Chemical Lagrangian Model of the Stratosphere (CLaMS) 2. Formulation of chemistry scheme and initialization, J. Geophys. Res., 107, ACH 4-1-ACH 4-14, doi:10.1029/2000JD000113, 2002b.

Müller, R., Crutzen, P. J., Grooß, J.-U., Brühl, C., Russell III, J. M., and Tuck, A. F.: Chlorine activation and ozone depletion in the Arctic vortex: observations by the Halogen Occultation Experiment on the Upper Atmosphere Research Satellite, J. Geophys. Res., 101, 12531-12554, 1996. 
Neu, J. L. and Plumb, R. A.: Age of air in a leaky pipe model of stratospheric transport, J. Geophys. Res., 104, 19246-19255, doi:10.1029/1999JD900251, 1999.

Ploeger, F., Konopka, P., Müller, R., Fueglistaler, S., Schmidt, T., Manners, J. C., Grooß, J.-U., Günther, G., Forster, P. M., and Riese, M.: Horizontal transport affecting trace gas seasonality in the Tropical Tropopause Layer (TTL), J. Geophys. Res., 117, D09303, doi:10.1029/2011JD017267, 2012.

Ploeger, F., Günther, G., Konopka, P., Fueglistaler, S., Müller, R., Hoppe, C., Kunz, A., Spang, R., Grooß, J.-U., and Riese, M.: Horizontal water vapor transport in the lower stratosphere from subtropics to high latitudes during boreal summer, J. Geophys. Res., 118, 8111-8127, 2013.

Pommrich, R., Müller, R., Grooß, J.-U., Konopka, P., Günther, G., Pumphrey, H.-C., Viciani, S., D’Amato, F., and Riese, M.: Carbon monoxide as a tracer for tropical troposphere to stratosphere transport in the Chemical Lagrangian Model of the Stratosphere (CLaMS), Geosci. Model Dev. Discuss., 4, 1185-1211, doi:10.5194/gmdd-4-1185-2011, 2011.

Pommrich, R., Müller, R., Grooß, J.-U., Konopka, P., Ploeger, F., Vogel, B., Tao, M., Hoppe, C. M., Günther, G., Spelten, N., Hoffmann, L., Pumphrey, H.-C., Viciani, S., D’Amato, F., Volk, C. M., Hoor, P., Schlager, H., and Riese, M.: Tropical troposphere to stratosphere transport of carbon monoxide and long-lived trace species in the Chemical Lagrangian Model of the Stratosphere (CLaMS), Geosci. Model Dev. Discuss., 7, 5087-5139, doi:10.5194/gmdd-7-5087-2014, 2014.

Randel, W. and Jensen, E.: Physical processes in the tropical tropopause layer and their roles in a changing climate, Nat. Geosci., 6, 169-176, 2013.

Reithmeier, C. and Sausen, R.: ATTILA: atmospheric tracer transport in a Lagrangian model, Tellus B, 54, 278-299, 2002.

Riese, M., Plöger, F., Rap, A., Vogel, B., Konopka, P., Dameris, M., and Forster, P.: Impact of uncertainties in atmospheric mixing on simulated UTLS composition and related radiative effects, J. Geophys. Res., 117, D16305, doi:10.1029/2012JD017751, 2012.

Röckner, E., Brokopf, R., Esch, M., Giorgetta, M., Hagemann, S., Kornblueh, L., Manzini, E., Schlese, U., and Schulzweida, U.: Sensitivity of simulated climate to horizontal and vertical resolution in the ECHAM5 atmosphere model, J. Climate, 19, 3771-3791, 2006.

Schoeberl, M. R., Dessler, A. E., and Wang, T.: Simulation of stratospheric water vapor and trends using three reanalyses, Atmos. Chem. Phys., 12, 6475-6487, doi:10.5194/acp-12-6475-2012, 2012.

Shaw, T. A. and Shepherd, T. G.: Raising the roof, Nat. Geosci., 1, 12-13, 2008.

Solomon, S., Rosenlof, K., Portmann, R., Daniel, J., Davis, S., Sanford, T., and Plattner, G.-K.: Contributions of stratospheric water vapor to decadal changes in the rate of global warming, Science, 327, 1219-1223, 2010.
Son, S.-W., Polvani, L., Waugh, D., Akiyoshi, H., Garcia, R., Kinnison, D., Pawson, S., Rozanov, E., Shepherd, T. G., and Shibata, K.: The impact of stratospheric ozone recovery on the Southern Hemisphere westerly jet, Science, 320, 1201-1204, 2008.

SPARC: SPARC report on the evaluation of chemistry-climate models, SPARC Rep. No. 5, WRCP-132, WMO-TD No. 1526, World Meteorol. Organ., 2010.

SPARC: Lifetimes of Stratospheric Ozone-Depleting Substances, Their Replacements, and Related Species, SPARC Rep. No. 6, WRCP-15/2013, World Meteorol. Organ., http://www. sparc-climate.org/publications/sparc-reports/sparc-report-no6/ (last access: 10 November 2014), 2013.

Steinhorst, H.-M., Konopka, P., Günther, G., and Müller, R.: How permeable is the edge of the Arctic vortex: model studies of winter 1999-2000, J. Geophys. Res., 110, D06105, doi:10.1029/2004JD005268, 2005.

Stenke, A., Grewe, V., and Ponater, M.: Lagrangian transport of water vapor and cloud water in the ECHAM4 GCM and its impact on the cold bias, Clim. Dynam., 31, 491-506, 2008.

Stenke, A., Dameris, M., Grewe, V., and Garny, H.: Implications of Lagrangian transport for simulations with a coupled chemistry-climate model, Atmos. Chem. Phys., 9, 5489-5504, doi:10.5194/acp-9-5489-2009, 2009.

Strahan, S. E., Schoeberl, M. R., and Steenrod, S. D.: The impact of tropical recirculation on polar composition, Atmos. Chem. Phys., 9, 2471-2480, doi:10.5194/acp-9-2471-2009, 2009.

Strahan, S. E., Douglass, A. R., Stolarski, R. S., Akiyoshi, H., Bekki, S., Braesicke, P., Butchart, N., Chipperfield, M. P., Cugnet, D., Dhomse, S., Frith, S. M., Gettelman, A., Hardiman, S. C., Kinnison, D. E., Lamarque, J.-F., Mancini, E., Marchand, M., Michou, M., Morgenstern, O., Nakamura, T., Olivié, D., Pawson, S., Pitari, G., Plummer, D. A., Pyle, J. A., Scinocca, J. F., Shepherd, T. G., Shibata, K., Smale, D., Teyssèdre, H., Tian, W., and Yamashita, Y.: Using transport diagnostics to understand chemistry climate model ozone simulations, $\mathrm{J}$ Geophys. Res., 116, D17302, doi:10.1029/2010JD015360, 2011.

Sutton, R. T., Maclean, H., Swinbank, R., O’Neill, A., and Taylor, F. W.: High-resolution stratospheric tracer fields estimated from satellite observations using Lagrangian trajectory calculations, J. Atmos. Sci., 51, 2995-3005, 1994.

Thompson, D. W. J. and Solomon, S.: Interpretation of recent Southern Hemisphere climate change, Science, 296, 895-899, 2002.

WMO: Scientific assessment of ozone depletion: 2010, Global Ozone Research and Monitoring Project-Report No. 52, Geneva, Switzerland, 2011. 